\title{
Laparoscopy-Assisted Distal Gastrectomy for Early Gastric Cancer in the Elderly
}

\author{
Eun Ji Kim, Kyung Won Seo, and Ki Young Yoon \\ Department of Surgery, Kosin University College of Medicine, Busan, Korea
}

Purpose: With an increase in life expectancy, more elderly patients are presenting with gastric cancer. As a result it is yet be resolved whether laparoscopy assisted distal gastrectomy is a suitable treatment for elderly patients with early gastric cancer. This study retrospectively compared surgical outcomes of laparoscopy assisted distal gastrectomy between elderly and nonelderly patients with gastric cancer.

Materials and Methods: The study group was comprised of 316 patients who underwent laparoscopy assisted distal gastrectomy between April 2005 and December 2010. Of these patients, 93 patients whose ages were 65 years or more were compared with 223 patients who were younger.

Results: There were no differences in the short term outcome or minor complication rate between the elderly patients and the nonelderly patients. The hospital stay was significantly longer and the major complication rate was significantly higher for the elderly patients compared with nonelderly patients.

Conclusions: Laparoscopy assisted distal gastrectomy for early gastric cancer in the elderly patients had comparable operation time and blood loss with the nonelderly group. However, the safety and advantage of laparoscopy assisted distal gastrectomy in the elderly patients need to be further studied in higher volume trials.

Key Words: Stomach neoplasms/surgery; Gastrectomy; Laparoscopy; Aged

\section{Introduction}

Korea has one of the highest incidences of gastric cancer in the world, and the elderly, who are disproportionately affected by gastric cancer, represent the fastest growing segment of the Korean population.

According to the annual report of the Korea National Statistical Office in 2007, the proportion of elderly of 65 years or more of age was $9.9 \%$, reflecting the so called 'aging society' suggested by the

Correspondence to: Ki Young Yoon

Department of Surgery, Kosin University College of Medicine, 262, Gamcheon-ro, Seo-gu, Busan 602-702, Korea

Tel: +82-51-990-6462, Fax: +82-51-246-6093

E-mail: yoonkiyoung@naver.com

Received July 5, 2012

Revised October 18, 2012

Accepted October 20, 2012
World Health Organization.(1)

The majority of elderly patients also have multiple comorbidities such as hypertension, diabetes mellitus, coronary artery and heart disease, making surgical management of gastric cancer challenging and more hazardous in terms of operative and postoperative morbidities. $(2,3)$ The aim of this study was to investigate that laparoscopy assisted distal gastrectomy (LADG) can be extended into the elderly patients for early gastric cancer.

\section{Materials and Methods}

A total of 316 patients with early gastric cancer of preoperative diagnosis underwent LADG at Kosin University Gospel Hospital between April 2005 and December 2010. We defined patients with the age of 65 years or more as elderly. Ninety-three patients $(29.4 \%)$ were elderly patients. The clinicopathological features of this elderly 
group were reviewed and compared with that of 223 nonelderly patients, those with the age of 64 years or less, using a prospectively collected database. The LADG patients were limited to those that invaded the mucosa or submucosa, without lymph node metastasis in preoperative examinations and those without concurrent malignant tumors in other organs. Furthermore, LADG was indicated when the tumor was located in the middle or lower part of the stomach.

The elderly and nonelderly groups were compared in terms of preoperative, intraoperative, and postoperative parameters. Records were reviewed, and pre-operative patient information regarding age, gender, studies, operative details, and pathology reports were collected. Intraoperative parameters included operation time, estimated blood loss, reconstruction method, and number of retrieved lymph nodes. Postoperative parameters included the incidence of morbidity and length of postoperative hospital stay.

We described the depth of tumor and lymph node metastasis as $\mathrm{T}$ and $\mathrm{N}$ stages according to the American Joint Committee on Cancer (AJCC) 7th ed.

\section{Operative procedure}

LADG was performed according to the following procedures. The patients in both groups underwent surgery under general anesthesia. Laparoscopic surgery was performed with the patient in the supine position under $\mathrm{CO}_{2}$ pneumoperitoneum at $10 \sim 12 \mathrm{cmH}_{2} \mathrm{O}$. Four surgical ports were inserted into the upper abdomen; the site at the subumbilicus was used for the laparoscope. Omentectomy was performed partially and reconstruction was performed by standard Billroth I or II method. The greater omentum was divided and dissected with an ultrasonically activated device (Harmonic ACE; Ethicon Endo-Surgery, Cincinnati, OH, USA). After omentectomy, the roots of the right gastroepiploic vein and artery were isolated and sealed with the Harmonic ACE and clips. The lesser omentum was opened, and the right gastric artery was divided. The left gastric artery was then exposed and divided after double clipping at the root while the suprapancreatic lymph nodes were dissected. A 5 $\mathrm{cm}$ transverse incision was made at the epigastrium. The doudenum was divided distal to the pyloric ring under direct visualization after the surgeon placed a purse-string suture device. The stomach was pulled out extracorporeally and divided using an endoscopic stapler (Endo GIA Universal 60 3.5 mm, Covidien, North Haven, CT, USA) at the proximal side of the tumor. A Billroth I anastomosis was then performed with a circular stapler (Premium Plus CEEA 28m, Covidien) and a Billroth II gastrojejunostomy applied by hand suturing through $5 \mathrm{~cm}$ midline incision. The operative field was re- examined laparoscopically to confirm satisfactory hemostasis. One Jackson-Pratt closed suction drain $(200 \mathrm{ml})$ was placed routinely in the right subhepatic area just before closure, and the volume of drainage throught the closed suction drain was checked daily. Removal of the drain was performed when the daily drainage amount was less then $200 \mathrm{ml}$. And no L-tube was placed.

\section{Definition of complications}

Operative mortality was defined as death within 30 days of surgery. And morbidities were defined as complications that required additional treatment or an extended hospital stay. For standardization purposes, complications were graded on Clavien-Dindo classification. In this system, grades I and II are grouped as minor complication and grades III-V are considered major complications. The Clavien-Dindo classification system uses objective criteria to assess the severity and incidence of postoperative complications. This classification system was first reported in 2004 and validated thereafter. $(4,5)$

\section{Statistical analysis}

Data were analyzed using the SPSS 17.0 statistical software package (SPSS Inc., Chicago, IL, USA). The Mann-Whitney test, Chi-square test, and the Student's t-test were used to compare the two groups appropriately. P-values less than 0.05 were considered to be significant. All values are presented as mean values \pm standard deviation.

\section{Results}

\section{Patient characteristics}

The demographic characteristics are shown in Table 1. The mean age of the all patients ( $\mathrm{n}=316$ ) was 56.8 years. There were 118 males (37.3\%) and 198 females (62.7\%). The mean body mass index (BMI) was 22.8 (elderly: 22.7 vs. nonelderly: 22.9). There was no significant difference in gender, BMI, number of lesions, or TNM stage between the elderly and nonelderly groups.

The number of comorbidities was statistically significantly higher for the elderly group then the nonelderly group. American society of anesthesiologists (ASA) score 2 and 3 were observed more frequently in members of elderly group, and this difference was statistically significant.

\section{Operative and perioperative results}

The intraoperative and perioperative outcomes are shown in Table 2. The mean operation time was 201.6 minutes (elderly: 203.6 
Kim EJ, et al

Table 1. Patient characteristics of age groups

\begin{tabular}{|c|c|c|c|}
\hline Variable & Elderly (n=93) & $\begin{array}{l}\text { Nonelderly } \\
(\mathrm{n}=223)\end{array}$ & P-value \\
\hline Age (yr) & $70.2 \pm 4.0$ & $51.3 \pm 8.8$ & 0.001 \\
\hline Gender & & & 0.525 \\
\hline Male & 61 & 137 & \\
\hline Female & 32 & 86 & \\
\hline BMI $\left(\mathrm{kg} / \mathrm{m}^{2}\right)$ & $22.7 \pm 2.5$ & $22.9 \pm 2.6$ & 0.641 \\
\hline Number of lesions & & & 0.785 \\
\hline 1 & 90 & 216 & \\
\hline 2 & 3 & 6 & \\
\hline 3 & 0 & 1 & \\
\hline Stage & & & 0.148 \\
\hline IA & 82 & 206 & \\
\hline IB & 10 & 9 & \\
\hline II & 1 & 7 & \\
\hline IIIA & 0 & 1 & \\
\hline Comorbidities & & & 0.001 \\
\hline Cardiovascular & 39 & 61 & \\
\hline Diabetes mellitus & 9 & 10 & \\
\hline Pulmonary & 11 & 13 & \\
\hline Renal & 1 & 2 & \\
\hline Liver & 1 & 1 & \\
\hline ASA score & & & 0.001 \\
\hline 1 & 32 & 138 & \\
\hline 2 & 54 & 81 & \\
\hline 3 & 7 & 6 & \\
\hline 4 & 0 & 0 & \\
\hline
\end{tabular}

Values are presented as mean \pm standard deviation or number; $\mathrm{BMI}=$ body mass index; ASA = American society of anesthesiologists.

vs. nonelderly: 200.7). The length of the postoperative hospital stay was significantly shorter in the nonelderly group than the elderly group. The number of retrieved lymph node was significantly less in the elderly group than the nonelderly group. However, there was no significant difference in blood loss, rate of conversion to open surgery, reconstruction method, or need for combined operation. The operation time was not prolonged in the elderly group.

\section{Complications}

Forty eight complications were observed, as described in Table 3. There was no difference in the minor complication rate between the elderly patients and the nonelderly patients. However, the number of major complications was significantly higher for the elderly patients than for the nonelderly ones.
Table 2. Intraoperative and perioperative outcomes of age groups

\begin{tabular}{lccc}
\hline \multicolumn{1}{c}{ Variable } & Elderly $(\mathrm{n}=93)$ & $\begin{array}{c}\text { Nonelderly } \\
(\mathrm{n}=223)\end{array}$ & P-value \\
\hline Operation time (min) & $203.6 \pm 71.7$ & $200.7 \pm 55.6$ & 0.901 \\
Blood loss (ml) & $159.7 \pm 150.8$ & $154.3 \pm 163.2$ & 0.529 \\
Number of retrieved & $21.8 \pm 12.5$ & $25.1 \pm 13.1$ & 0.043 \\
lymph nodes & & & \\
Conversion to open & 1 & 1 & 0.503 \\
surgery & 4 & 12 & 0.468 \\
Combined operation & $13.1 \pm 15.2$ & $9.7 \pm 4.2$ & 0.008 \\
Hospital stay & & & 0.458 \\
Lymph node dissection & 18 & 50 & \\
D1+ $\alpha$ & 39 & 77 & \\
D1+ $\beta$ & 36 & 96 & \\
D2 & & & 0.137 \\
Reconstruction method & 68 & 180 & \\
BI & 25 & 43 & \\
BII & & & \\
\hline
\end{tabular}

Values are presented as mean \pm standard deviation or number.

Table 3. Complications by Clavien-Dindo classification of age groups

\begin{tabular}{|c|c|c|c|c|}
\hline \multicolumn{2}{|l|}{ Grade } & $\begin{array}{l}\text { Elderly } \\
(\mathrm{n}=93)\end{array}$ & $\begin{array}{l}\text { Nonelderly } \\
(\mathrm{n}=223)\end{array}$ & $\begin{array}{c}\mathrm{P}- \\
\text { value }\end{array}$ \\
\hline \multicolumn{2}{|c|}{ Minor complications } & 13 & 29 & 0.931 \\
\hline \multirow[t]{5}{*}{ Grade I } & Wound seroma & 5 & 18 & \\
\hline & Ileus & 2 & 3 & \\
\hline & UTI & 0 & 1 & \\
\hline & $\begin{array}{l}\text { Intra abdominal } \\
\text { fluid collection }\end{array}$ & 1 & 0 & \\
\hline & Atelectasis & 2 & 2 & \\
\hline \multirow[t]{2}{*}{ Grade II } & Diarrhea & 1 & 1 & \\
\hline & Pancreatitis & 2 & 4 & \\
\hline \multicolumn{2}{|c|}{ Major complications } & 4 & 2 & 0.001 \\
\hline Grade IIIa & Anastomotic leakage & 1 & 2 & \\
\hline Grade IIIb & Intraluminal bleeding & 3 & 0 & \\
\hline
\end{tabular}

$\mathrm{UTI}=$ urinary tract infection.

Postoperative bleeding occurred in three patients in the elderly group. And anastomotic leakage occurred in one patient in the elderly, two patients in the nonelderly group. Reoperation was performed in three patients; a bleeding control was performed because of intra-luminal bleeding, and two primary repair of anastomotic leakage was performed. One bleeding was stopped by clips with 
an endoscope. One nonelderly patient who developed leakage had discharged himself against medical advice and loss to follow up. One patient died 3 days after the operation. The patient developed bleeding, and had liver cirrhosis (Child B). Although intensive care, this patient has died without reoperation.

\section{Discussion}

Although the total number of gastric cancer has reached a plateau the number of elderly people with gastric cancer has continued to increase.(6) Elderly patients with underlying morbidities are more susceptible to anesthesiologic risks or serious complications following operations. $(7,8)$

Laparoscopic procedures for early gastric cancer have been widely adopted in Korea.(9) The goals of laparoscopic surgery for gastric cancer are to minimize surgical insults and to maximize the patient's quality of life, while not changing the extent to which the tumor is removed and the appropriate negative margins achieved. Previous reports have presented excellent short term outcomes including less postoperative pain, improved cosmesis, less inflammatory reaction, preserved immune function, rapid recovery of bowel function, shorter hospital stay, and rapid return to normal social activity.(10-13) In addition, laparoscopic gastrectomy may offer substantial advantages to the elderly population in terms of fewer cardiac and pulmonary complications, shorter hospital stays, and a faster return to physical activities. LADG has been reported to cause less morbidity even among elderly patients with a higher incidence of comorbid diseases.(14,15) Many reports have concluded that laparoscopic gastrectomy is a feasible and safe procedure in elderly patients if the patients have been selected carefully and the procedure is performed by an experienced laparoscopic surgeon. (16-20) Previous work has also suggested that a low pneumoperitoneum pressure or a gasless laparoscopic approach might be preferable for elderly patients with cardiopulmonary disease. $(4,5,14)$

In this study, there was no difference in short term outcome or rate of minor complications between the elderly patients and the nonelderly patients. However, the incidence of major complications was significantly greater in elderly patents than nonelderly patents. We hypothesize that old age itself is an important risk factor for a major operation, because they have a much more comorbidity preoperatively, even if minimally invasive surgery techniques are used. However, other current analyses have not identified chronological age as an independent risk factor for postoperative morbidity after LADG and suggest that age alone does not affect the postopera- tive course. $(3,14,15)$ Absence of a comparison group undergoing open gastrectomy is major limitation of our study. Therefore, more research is needed in both elderly patients and nonelderly patients comparing LADG and open gastrectomy. This should include large randomized controlled studies.

Most previous studies have investigated that short-term outcomes showed no difference between LADG and open gastrectomy for early gastric cancer. In addition, one multicenter study also discussed that its 5-year survival rate showed no difference.(21) However, it remains unclear whether LADG is suitable for elderly patients with gastric cancer from this standpoint. $(14,15)$ The longterm outcomes of elderly patients should be further investigated in the future.

In conclusion, it would be inappropriate to conclude that LADG is not feasible in the elderly patents for early gastric cancer because of absence of compare with open gastrectomy. Further analysis in a randomized trial and high-volume study and compare with open gastrectomy is needed to recommend LADG as a standard treatment in the elderly population.

\section{References}

1. http://kosis.kr/Accessed May 1, 2011

2. Galizia G, Prizio G, Lieto E, Castellano P, Pelosio L, Imperatore $\mathrm{V}$, et al. Hemodynamic and pulmonary changes during open, carbon dioxide pneumoperitoneum and abdominal walllifting cholecystectomy. A prospective, randomized study. Surg Endosc 2001;15:477-483.

3. Uemura N, Nomura M, Inoue S, Endo J, Kishi S, Saito K, et al. Changes in hemodynamics and autonomic nervous activity in patients undergoing laparoscopic cholecystectomy: differences between the pneumoperitoneum and abdominal wall-lifting method. Endoscopy 2002;34:643-650.

4. Clavien PA, Barkun J, de Oliveira ML, Vauthey JN, Dindo D, Schulick RD, et al. The Clavien-Dindo classification of surgical complications: five-year experience. Ann Surg 2009;250:187196.

5. Dindo D, Demartines N, Clavien PA. Classification of surgical complications: a new proposal with evaluation in a cohort of 6336 patients and results of a survey. Ann Surg 2004;240:205213.

6. Kitamura K, Yamaguchi T, Taniguchi H, Hagiwara A, Yamane T, Sawai K, et al. Clinicopathological characteristics of gastric cancer in the elderly. Br J Cancer 1996;73:798-802. 
7. Khan MR, Bari H, Zafar SN, Raza SA. Impact of age on outcome after colorectal cancer surgery in the elderly - a developing country perspective. BMC Surg 2011;11:17.

8. Simmonds PD, Best L, George S, Baughan C, Buchanan R, Davis C, et al. Surgery for colorectal cancer in elderly patients: a systematic review. The Lancet 2000;16:968-974.

9. Jeong O, Park YK. Clinicopathological features and surgical treatment of gastric cancer in South Korea: the results of 2009 nationwide survey on surgically treated gastric cancer patients. J Gastric Cancer 2011;11:69-77.

10. Kim HH, Hyung WJ, Cho GS, Kim MC, Han SU, Kim W, et al. Morbidity and mortality of laparoscopic gastrectomy versus open gastrectomy for gastric cancer: an interim report--a phase III multicenter, prospective, randomized Trial (KLASS Trial). Ann Surg 2010;251:417-420.

11. Huscher CG, Mingoli A, Sgarzini G, Sansonetti A, Di Paola M, Recher A, et al. Laparoscopic versus open subtotal gastrectomy for distal gastric cancer: five-year results of a randomized prospective trial. Ann Surg 2005;241:232-237.

12. Hwang SH, Park do J, Jee YS, Kim MC, Kim HH, Lee HJ, et al. Actual 3-year survival after laparoscopy-assisted gastrectomy for gastric cancer. Arch Surg 2009;144:559-564.

13. Kim YW, Baik YH, Yun YH, Nam BH, Kim DH, Choi IJ, et al. Improved quality of life outcomes after laparoscopy-assisted distal gastrectomy for early gastric cancer: results of a prospective randomized clinical trial. Ann Surg 2008;248:721-727.

14. Kunisaki C, Makino H, Takagawa R, Oshima T, Nagano Y,
Ono HA, et al. Efficacy of laparoscopy-assisted distal gastrectomy for gastric cancer in the elderly. Surg Endosc 2009;23:377383.

15. Mochiki E, Ohno T, Kamiyama Y, Aihara R, Nakabayashi $\mathrm{T}$, Asao T, et al. Laparoscopy-assisted gastrectomy for early gastric cancer in young and elderly patients. World J Surg 2005;29:1585-1591.

16. Koeda K, Nishizuka S, Wakabayashi G. Minimally invasive surgery for gastric cancer: the future standard of care. World J Surg 2011;35:1469-1477.

17. Yasuda K, Sonoda K, Shiroshita H, Inomata M, Shiraishi N, Kitano S. Laparoscopically assisted distal gastrectomy for early gastric cancer in the elderly. Br J Surg 2004;91:1061-1105.

18. Tokunaga M, Hiki N, Fukunaga T, Miki A, Ohyama S, Seto Y, et al. Does age matter in the indication for laparoscopy-assisted gastrectomy? J Gastrointest Surg 2008;12:1502-1507.

19. Hwang SH, Park do J, Jee YS, Kim HH, Lee HJ, Yang HK, et al. Risk factors for operative complications in elderly patients during laparoscopy-assisted gastrectomy. J Am Coll Surg 2009;208:186-192.

20. Cho GS, Kim W, Kim HH, Ryu SW, Kim MC, Ryu SY. Multicentre study of the safety of laparoscopic subtotal gastrectomy for gastric cancer in the elderly. Br J Surg 2009;96:1437-1442.

21. Kitano S, Shiraishi N, Uyama I, Sugihara K, Tanigawa N; Japanese Laparoscopic Surgery Study Group. A multicenter study on oncologic outcome of laparoscopic gastrectomy for early cancer in Japan. Ann Surg 2007;245:68-72. 